\title{
ASSESSMENT OF POST VOIDING RESIDUAL URINE VOLUME IN EGYPTIAN CHILDREN WITH PRIMARY NOCTURNAL ENURESIS
}

A.M. Abd Al-Aziz ${ }^{1}$, H.M. Hamed ${ }^{1}$, A.A. Motawie ${ }^{1}$, A.M. Nour Eldin Abd Elbaky ${ }^{1}$, A.A. Fatouh ${ }^{1}$, H.T. El Bassyouni ${ }^{2}$, M.I.K. Shehab ${ }^{3}$, M.A.M. Eid $^{3}$

${ }^{1}$ Pediatrics, ${ }^{2}$ Clinical Genetic, ${ }^{3}$ Cyto-genetics, National Research Centre, Cairo, Egypt

Background: Debate is ongoing about the role of abnormalities of bladder function in primary nocturnal enuresis (PNE). Increasing post voiding residual urine volume was reported to be typically a sign of abnormal detrusor function.

Aim: Assessment of post-void residual urine volume in children with PNE for evaluating bladder dysfunction.

Subjects \& methods: This study included 69 children aged 5-18 years suffering from PNE and 43 healthy children of the same age and sex as control. All enuretic children were subjected to history taking, Genetic evaluation, thorough clinical examination and Cytogenetic study of peripheral blood culture. Abdominal ultra-sound examination for pre voiding urine volume (V1) and post voiding residual urine volume (V2) was done for all cases and control.

Results: Presence of $\mathbf{V} \mathbf{2}$ were significantly more in NE patients than controls $(p=0.002)$. The mean \pm SD of V2 was significantly higher in patients than control $(25.28 \pm 19.2 \mathrm{ml}$ versus $19.86 \pm 9.55, \mathrm{p}=0.01)$. Presence of $\mathbf{V} \mathbf{2}$ was significantly higher in those with positive family history of enuresis $(\mathrm{p}=0.0001)$, AR mode of inheritance $(0.006)$ and urinary symptoms $(p=0.005)$. Bladder efficiency was significantly reduced in children with enuresis as compared to controls $(\mathrm{p}=0.02)$. $\mathbf{V 1}$ was statistically higher in cases $(149.18+107.71)$ than controls $(112.24+67.27), \mathrm{p}=0.05$, and positively correlated with $\mathbf{V} \mathbf{2}$ in cases $(\mathrm{r}=0.337$, $\mathrm{p}=0.005)$. Three cases, had abnormal karyotype $(46, \mathrm{XY}, \mathrm{t}(7 ; 14),(46, \mathrm{XY} / 46, \mathrm{XY}, \operatorname{del}(22)(\mathrm{q} 11)$ and $(46, X Y, \operatorname{del}(22)(\mathrm{q})$ ?. the cytogenetic analysis revealed 46,XY,t(11;22)(q24;q11).

Conclusion: Enuresis episodes may be related to incomplete bladder emptying and hypo-contractility. Our results support the associated genetic locus on chromosome 22q. 